\title{
STRESS ANALYSIS OF INDIGENOUSLY DESIGNED ENERGY STORING POLYPROPYLENE CO-POLYMER (PPCP) PROSTHETIC FOOT
}

\author{
Sachin S Bhagat* Lecturer in Prosthetics \& Orthotics, GMC, Goa. ${ }^{*}$ Corresponding Author \\ Mr. A.G Indalkar Lecturer and Head, Dep. Of Prosthetics \& Orthotics, AIIPMR, Mumbai) \\ Mr. Avinash Phirke Professor, Watumull Institute of Engineering \& Technology Mumbai.
}

ABSTRACT Polypropylene Co-polymer (PPCP) Prosthetic Foot Model, Indigenously designed at All India Institute of Physical Medicine and Rehabilitation (AIIPMR), Mumbai. More commonly, this design is known as Modified Flex foot. Various researcher's contributed towards its design modification, material optimization, patient trial \& clinical implications and further improvements. As such, this study was conducted to observe \& understand the stress analysis of this modified flexfoot under loading conditions at various orientation of gait. Finite element analysis (FEA) method was used with Ansys 12.0 software. Study objectives was to construct and analyze the finite element model, to find out \& understand failure prone areas in the present design of PPCP prosthetic foot.

This study was conducted into five phases. At initial phase, actual foot design was constructed and input parameters like geometrical parameters were calculated considering the standard length transtibial amputee. Similarly Material properties, loading conditions \& boundary conditions were determined. AutCAD model was constructed using input parametrs \& imported into Ansys 12.0 software. Finite element model were constructed and analyzed. Results were noted, which were displyed in the form of several contour plots \& through colours that correspond to different stress values. FEA results obtained for various stress values like, Elemental stress, shearing stress \& Von Mises stresses (Combination stresses).

Peak Von Mises stress value of $28112 \mathrm{Mpa}$, observed at lower ankle fillet region during heel strike orientation of the gait. Study concluded that lower ankle fillet region \& Midfoot spring region will be subjected to maximum stress during heel strike, Mid stance \& push off. It was concluded that lower ankle fillet region \& Midfoot spring region will be subjected to maximum stress during heel strike, Mid stance \& push off.

\section{KEYWORDS : FEA, Finite element analysis, Ansys, PPCP, Prosthetic foot.}

\section{INTRODUCTION:}

The Human foot designed by nature, which is propelled through a self dynamic mechanism is very intricate. This biological component is highly complex and perfectly tuned with response of highly vulnerable ground reaction force. In fact, it is very challenging task to design the prosthetic foot, which is sophisticated \& strong, so far as the intrinsic and extrinsic activities are concerned. Therefore when the designer is designing the prosthetic foot, he has to take into consideration the stress concentration under loading condition. Keeping this in mind, current study aims to analyze an indigenously designed energy storing prosthetic foot using finite element method. Finite Element Analysis (FEA) is a computational tool which enables the complex structure to be broken down into smaller mechanically simpler regions then by assigning appropriate material properties and loading condition stress and strain can be determined.

In this study the prosthetic foot design has been considered for trans-tibial patient with standard length of the residual limb. Analysis was performed during three different orientations of gait.

$\begin{array}{llccc}\text { Condition I } & - & \text { Heel strike } & - & 30^{\circ} \text { orientation } \\ \text { Condition II } & - & \text { Mid Stance } & - & 0^{\circ} \text { orientation } \\ \text { Condition III } & - & \text { Push off } & - & 33^{\circ} \text { orientation }\end{array}$

\section{AIMS \& OBJECTIVES:}

1. To construct the finite element model of the present design of an Polypropylene-copolymer prosthetic foot.

2. To analyse the finite element model.

3. To predict the load distribution between the different section of the foot during heel strike, midstance \& push off orientation of the gait..

4. To find out the failure prone areas in the present design of an extended keel foot

\section{Parameters of study \\ a. AutoCAD foot modeling \\ b. Stress analysis \\ c. Finite element analysis}

\section{Instrumentation \\ a. Ansys 12.0}

b. AutoCAD 2010

\section{Procedure:}

Study conducted into the following phases,

1. Fabrication of the actual prosthetic foot design.

2. Input parameters determination for finite element model.

3. Construction of 3D AutoCAD model of the foot. (Preprocessing)

4. Construction of finite element model (FEM). (Processing or Solutions)

5. Analysis of finite element model (FEA). (Post processing)

At the initial phase of the study the actual prosthetic foot which helps to generate the AutoCAD model of the foot was constructed. Input parameters like geometrical parameter and material properties, loading conditions \& boundary conditions were determined. A 3D AutoCAD model is constructed (Fig.1) using input parameters.

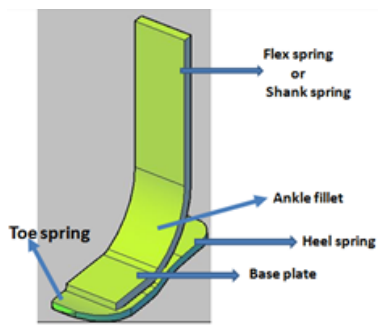

Fig. Anterior view of AutoCAD foot Model

Then the 3D AutoCAD model is imported into the Ansys 12.0 software. Using mesh tool in the Ansys, the model is divided 
into finite segments (elements) which when put together is referred to as the element mesh. The nodes of the mesh are the points at which "vertices" join together. This model is known as Mesh Model which is created under preprocessing stage of analysis. (Fig 2 A)

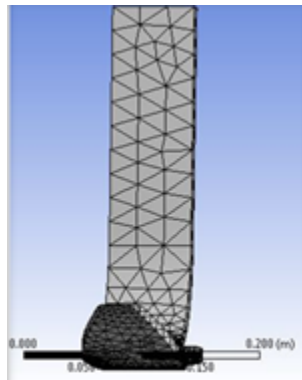

Anterior view of the MESH model

(Fig 2 A Anterior view of mesh Model)

To increase the accuracy level of the solution, Mesh model is refined with smaller element size i.e. higher density mesh or Fine Mesh Model (Fig. 2 B). Fine meshing is applied at the smaller dimensions and complicated points. With progression of study,

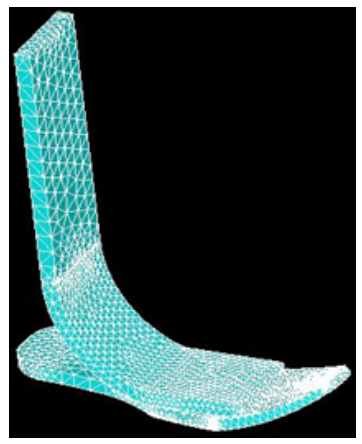

(Fig: 2 B: Fine Mesh Model)

failure prone areas are identified. Whereas To increase the accuracy of FEA model and to reduce the computational time, fine meshing is applied at those failure prone areas. Input parameters like loading conditions, loading orientation, boundary conditions and material properties are determined in the previous phase (Phase II) of the study. When the accurate fine meshing is finished the software required these input parameters. Maximum weights of $100 \mathrm{~kg}(981 \mathrm{~N})$ are applied at three different orientation of the gait. I.e. heel strike, mid stance and push off. Loading orientation taken as $30^{\circ}, 0^{\circ}$, and $33^{\circ}$ at heel strike, mid stance and push off respectively. Application of load is along the direction of flex spring and boundary conditions are different for each of the orientation.

Finite Element model is obtained for the applied conditions at the solution phase. In order to get the accurate results, the software solves the several equations during this phase.

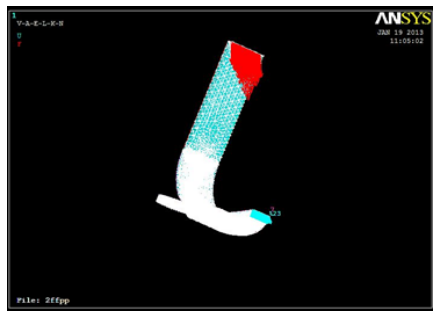

(Figure 4- Application of load and boundary conditions at Push off, for PPCP model.

Post processing stage, consists of obtaining pertinent information from the 'solved' model. After the mesh was successfully applied to the model and the program had finished running the model, the results were extracted to observe the Von Mises stresses (Fig4 A), shearing stresses (Fig4 B), and elemental stresses (Fig4 C) that occurred due to the applied loads. The results have been reported in the form of several contour plots, which are displayed through colours that correspond to different stress and displacement value levels

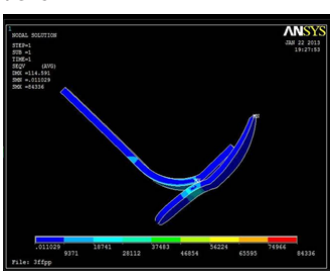

(Fig4 Ä:Von Mises stress solution during Heel strike)

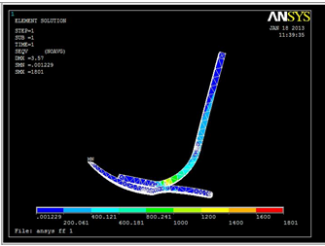

(Fig4 C) Elemental stresses solution for normal stresses, at mid stance)

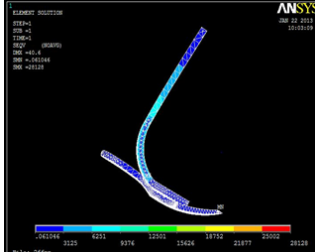
solution during push off)

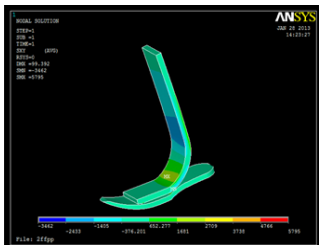

(Fig;4 D Nodal Solution for shear stress, at Mid stance)
(Fig4 B:Elemental stress

The colour scale of the contour plots was adjusted to ensure that the same values corresponded with the same stress values throughout all of the models.

\section{Analysis and Results}

Finite element models were analyzed to know the failure prone areas and to observe the normal elemental stresses, shearing stresses and Von Mises stresses (combination stresses). FEA result shows the stress distribution values experienced by the different parts of the foot during three different conditions of the gait. The stress distribution obtained from the analysis depicts the region of high stress \& failure prone areas. Von Mises (Combination stress) Stress values (in MPa) obtained at various parts of the foot (at heel strike mid stance \& push off orientation) displayed under tablel.

(Table l: Von Mises stress values in PPCP Foot)

\begin{tabular}{|c|c|c|c|c|}
\hline \multirow{2}{*}{ Part of Foot } & \multicolumn{3}{|c|}{$\begin{array}{c}\text { Sredicted Stress contours in Mega } \\
\text { Pascal (MPa). }\end{array}$} \\
\cline { 2 - 5 } & Heel Strike & Mid stance & Push off \\
\hline \multicolumn{2}{|c|}{ Proximal Flex /shank } & 0.011029 & 0.001484 & 0.078252 \\
\hline \multicolumn{2}{|c|}{ Middle flex spring } & 18741 & 174.985 & 4501 \\
\hline \multirow{2}{*}{ Ankle fillet } & Upper & 0.011029 & 524.951 & 4501 \\
\cline { 2 - 5 } & Middle & 18741 & 874.918 & 4501 \\
\cline { 2 - 5 } & Lower & 28112 & 1225 & 6751 \\
\hline \multicolumn{2}{|c|}{ Base Plate } & 0.011029 & 0.001484 & 0.078252 \\
\hline \multicolumn{2}{|c|}{ Heel Spring } & 0.011029 & 0.001484 & 0.078252 \\
\hline \multicolumn{2}{|c|}{ Mid foot Spring } & 28112 & 349.968 & 6751 \\
\hline \multicolumn{2}{|c|}{ Toe spring } & 0.011029 & 0.001484 & 0.078252 \\
\hline
\end{tabular}

It was concluded that, lower ankle fillet region \& Midfoot spring region were failure prone regions and subjected to maximum stress during heel strike, mid stance \& push off. Whereas this foot can withstand the given loading condition $(100 \mathrm{Kg})$ at heelstrike, midstance \& push off orientaion.

\section{REFERENCES:}

1. Marnie M. Saunders, Edwards P. Schwentker et al (2003): Finite Element Analysis as a Tool for Parametric Prosthetic Foot Design and Evaluation. Technique Development in the Solid Ankle Cushioned Heel (SACH) Foot, Computer Methods in Biomechanics and Biomedical Engineering,

2. Ahmet Erdemir, Trent M. Guess, Jason Halloran, Srinivas C.Tadepalli et.al Considerations for reporting finite element analysis studies in biomechanics, 
Journal of Biomechanics 45 (2012) 625-633.

3. Milan Omasta, David Paloušek, Tomas Návrat, Ji í Rosický, Finite element analysis for the evaluation of the structural behaviour, of a prosthesis for trans-tibial amputees, journal of Medical Engineering \& Physics, Volume 34, Issue 1, January 2012, Pages 38-45.

4. Silverthorn MB, Childress DS. Parametric analysis using the finite e l e m e n t method to investigate prosthetic interface stresses for persons $w i t h$ tr $\alpha \mathrm{n} s$ tibial amputation. Journal of Rehabilitation Research and Development 1996; 33(3):227-38

5. Quesada P, Skinner HB. Analysis of a below-knee patellar tendon-b e a r i n g Prosthesis - a finite-element study. Journal of Rehabilitation Research and Development 1991; 28(3):1-12

6. Strang, Gilbert, Fix, George (1973). An Analysis of the Finite Element Method. Prentice Hall. ISBN )-13-032946-0

7. Jia X, Zhang M, Lee WCC. Load transfer mechanics between trans-tibial prosthetic socket and residual limb-dynamic effects. Journal of ,Biomechanics2004; 37(9):1371-7.

8. Lee WC, Zhang M, Boone DA, et.al., Finite-element analysis to determine effect of monolimb flexibility on structural strength and interaction between residual limb and prosthetic socket. Journal of Rehabilitation Research and Development, 2004 Nov-Dec; $41(6 A): 775-86$ 